\title{
Research on The Evolution Law of Spatial Structure of Overlying Strata and Evaluation of Rock Burst Risks in Deep Well Strip Mining
}

Jinglin Wen (D 392386324@qq.com )

China Academy of Safety Science Technology, Beijing, China https://orcid.org/0000-0002-8076-7812 Zhengxing Yu

China Academy of Safety Science and Technology

Haitao Ma

China Academy of Safety Science and Technology

Quande Wei

Beijing Anke Xingye Science and Technology Co., Ltd.

\section{Original Paper}

Keywords: Mining engineering, strip mining, supporting pressure, risks of rock burst, spatial structure of overlying strata

Posted Date: February 15th, 2021

DOI: https://doi.org/10.21203/rs.3.rs-193570/v1

License: (9) This work is licensed under a Creative Commons Attribution 4.0 International License. Read Full License 


\title{
Research on the Evolution Law of Spatial Structure of Overlying Strata and Evaluation of Rock Burst Risks in Deep well Strip Mining
}

\author{
Zhengxing Yu ${ }^{\mathrm{a}}$, Jinglin Wen ${ }^{\mathrm{a}^{*}}$, Haitao $\mathrm{Ma}^{\mathrm{a}}$, Quande Wei ${ }^{\mathrm{b}}$ \\ ${ }^{a}$ China Academy of Safety Science and Technology, Beijing 100012, China; ${ }^{b}$ Beijing Anke \\ Xingye Science and Technology Co., Ltd., Beijing 100083,
}

\begin{abstract}
Strip mining in mines is one of the main mining methods to control surface subsidence and protect the ecological environment. In recent years, strip mining has induced frequent rock burst accidents due to the increase in mining intensity and mining depth. Based on two typical deep strip mining accidents, the characteristics of the changes in spatial structure of the overlying strata caused by strip mining are studied, and the influencing factors of the occurrence of strip mining rock burst are analyzed. A support pressure calculation model is proposed, and estimated and verified in a mine after an analysis of the change law of the overlying strata structure in strip mining and research on the distribution and evolution law of support pressure. Based the above research, a risk evaluation model of the strip mining face is proposed based on the possibility index method, the 4203 working face of a mine is evaluated. Compared with the numerical simulation results, this method is well consistent with the theoretical calculation model. It can be seen that this method has strong practicability and is of great significance for studying the rock burst characteristics of coal seams in strip mining and evaluating the risk of rock burst of coal seams.
\end{abstract}

Keywords: Mining engineering; strip mining; supporting pressure; risks of rock burst; spatial structure of overlying strata

\section{Introduction}

With the increase in mining depth and intensity of coal resources in China, rock burst is one of the main dynamic disasters frequently occurring during coal mining. With the increase in coal mining depth, the number of rock burst mines in China continues to increase. As of the end of 2016, there were as many as 178 rock burst mines in China ${ }^{[1]}$. To effectively predict and control rock burst disasters, scholars both at home and broad conducted a great deal of research on ground pressure related theories, monitoring methods, and treatment technologies, and achieved fruitful results. The research achievements mainly include occurrence mechanism of rock burst, risk evaluation of rock burst, techniques of monitoring and early warning of rock burst and techniques of rock burst control. The new "Safety Regulations for Coal Mines" promulgated in 2016 stipulates that rock burst mines should be subject to prediction of rock burst risks. It is thus clear that the prediction (evaluation) of rock burst risks is an important part of realizing the prevention and control of rock burst. Therefore, accurate evaluation

${ }^{*}$ E-mail address: wenj1@chinasafety.ac.cn 
of the risks of rock burst of coal seams is significant for the prevention and control of rock burst and even the safety in coal mine production ${ }^{[2]}$.

The factors affecting the rock burst risks of the coal rock mass mainly include the intrinsic properties of coal rock, geological conditions and mining technical conditions ${ }^{[3]}$. Chinese scholars have conducted a great deal of research on the factors that affect the risk of rock burst, and proposed many methods for evaluating the risks of rock burst. Dou Linming ${ }^{[4]}$ proposed a comprehensive index method for evaluating the risks of rock burst. The comprehensive index method is a comprehensive method for the evaluation of rock burst risks. This method analyzes the effects of various mining and geological factors on rock burst based on the analysis of various rock burst disasters that have occurred, and determines the influence weight of various factors. Jiang Fuxing ${ }^{[5]}$ proposed a possibility index diagnosis method of rock burst occurrence and a multi-factor coupling evaluation method. The possibility index diagnosis method is to rate the possibility of rock burst with mining-induced stress and burst tendency of coal seams as the main indicators by studying the main factors that induce rock burst and adopting the fuzzy mathematics method. The multi-factor coupling method is to comprehensively consider the factors that produce risks of rock burst risks, such as mining, geology, coal seams and rock formations etc. Then, according to the different conditions of each factor, different evaluation methods are employed to delineate the areas of rock burst risks. Finally, all influencing factors are coupled and evaluated to obtain areas with different risk levels. Zhang Hongwei[ ${ }^{[6-7]}$ established an evaluation method and evaluation indexes of geodynamic conditions of rock burst, determined the main influencing factors of rock burst and their interaction relationship by using the geodynamic zoning method and delineated dangerous areas using the analysis system for rock mass stress states. Scholars from Poland and the former Soviet Union proposed three rock burst tendency indicators: the elastic energy index $\mathrm{W}_{\mathrm{ET}}$, the burst energy index $\mathrm{K}_{\mathrm{E}}$ and the dynamic failure time DT of coal samples. China has also successively proposed and formulated national standards for the identification of bursting liability of coal seams and roofs ${ }^{[8-9]}$, and provided corresponding parameters for judging bursting liability categories of coal rock.

Deep well strip mining is a special mining method. By consulting related literature, we have found that the research on the mechanism of rock burst, monitoring and early warning methods and mining design methods under deep-well strip mining conditions is still in the exploratory stage, and no scientific and systematic research results can be actually applied ${ }^{[10]}$. For this reason, to realize the prevention and control of rock burst in deep well strip mining, based on engineering site investigation and analysis, with deep well strip mining as the engineering background, research have been carried out on the mechanism and prevention of rock burst in deep well strip mining.

For this reason, the paper explores the movement law of overlying strata, supporting pressure distribution and rock burst prevention technique under the conditions of deep well strip mining with different strata structures. The possibility index method is employed to evaluate the rock burst risks of a mining strip working face. The result shows that the evaluation results of rock burst risks considering the thickness of the coal seam is more practical. The research achievement can provide a theoretical basis for the prediction and prevention of rock bursts in deep mine strip mining, and can avoid and reduce the occurrence of rock bursts. The research achievement has referential significance for prevention of rock bursts in mines with similar conditions.

\section{Background overview}

In recent years, with the increase in coal mining depth, strip mining is suitable for burial depths beyond 500m. Deep large mining and wide strip mining technique has been gradually applied in deep mines, but rock burst accidents induced by strip mining occur frequently.

\subsection{Case 1}

On January 17, 2017, a rock burst accident occurred in front of the reversed loader in front of the 4203 fully 
mechanized mining face of a coal mine in Shanxi. The accident scene is shown in Figure 1. The accident caused serious damage to the $0 \sim 41 \mathrm{~m}$ end of the working face, severe section shrinkage, severe bending and sinking of the advance support 11\# I-steel top beam, significant bending of the single hydraulic prop, destruction and failure of most of the anchor rods and anchor cables, tilting of the reversed loader head, one side stick close to the roof, and the other side $350 \mathrm{~mm}$ away from the roof. The roof was basically complete in the range of $41-51 \mathrm{~m}$ in front of the working face, and the floor was flushed out; $51-70 \mathrm{~m}$ in front of the work face was the collapsed section of roof caving with a length of $19 \mathrm{~m}$ and the roof-caving height reaches the immediate roof, between $2.0-2.5 \mathrm{~m}$. After collapse, the roadway became an arched trapezoid. Most of the bolts were exposed, and the coal side collapsed. All the 19 roof anchors in the roof caving area were broken. A large number of roof bolts were broken and S-shaped bent. According to statistics, more than 30 sets of anchor rods were broken. $70-200 \mathrm{~m}$ before the work front was the failure section outside the roof caving zone, of which the area of $70-115 \mathrm{~m}$ was more serious. Net bags appeared on the side and roof, and the bottom drum was serious. The legs of the middle frame of the two belt conveyor were distorted and twisted, and the accident eventually led to death of 10 workers.
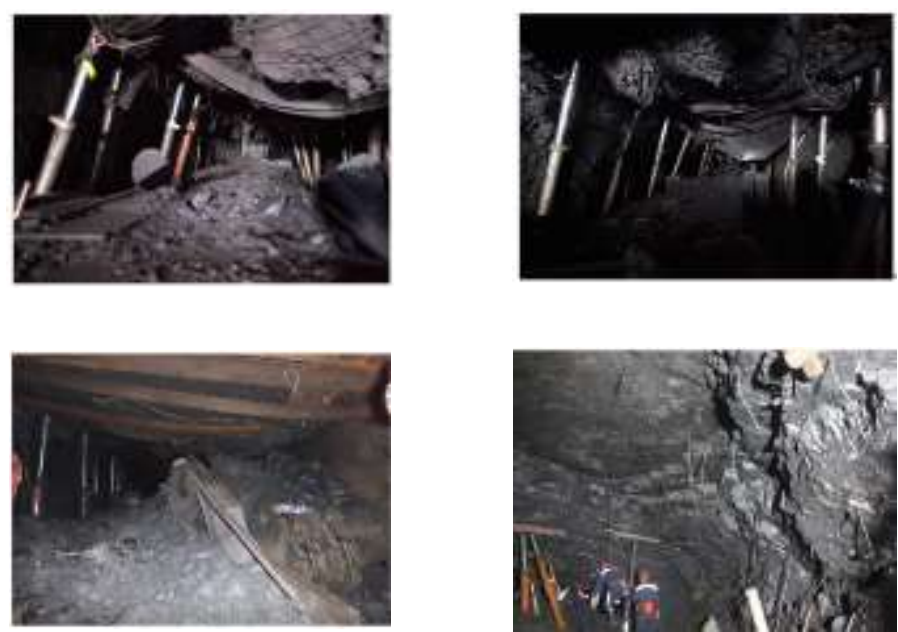

Figure 1Scene of a rock burst accident in a mine

\subsection{Case 2}

On March 31, 2012, a serious floor rock burst accident occurred in the track lane of 3301 working face of a coal mine in Shandong from the stop line $180 \mathrm{~m}$ to $310 \mathrm{~m}$ outwards. The accident resulted in the death of two workers working in this area. The location of rock burst is shown in Figure 2. The inclined length of the three strip working faces is $110 \mathrm{~m}$, the average burial depth is $950 \mathrm{~m}$, the average thickness of the coal seam is $6.5 \mathrm{~m}$, the average inclination angle is $11^{\circ}$, the width of strip coal pillar between the 3301 working face and the 3305 working face is $160 \mathrm{~m}$, and the width of strip coal pillars between the 3305 working face and the 3309 working faces is $120 \mathrm{~m}$. It can be seen from Figure 2 that the 3301 working face is the third strip working face of continuous mining in the third mining area and is influenced by the regional stress transfer in the mining goaf ${ }^{111}$. Thus it is clear that this is a typical large-scale, high-strength rock burst formed by the superposition of regional stress transfer and mining stress in strip mining. 


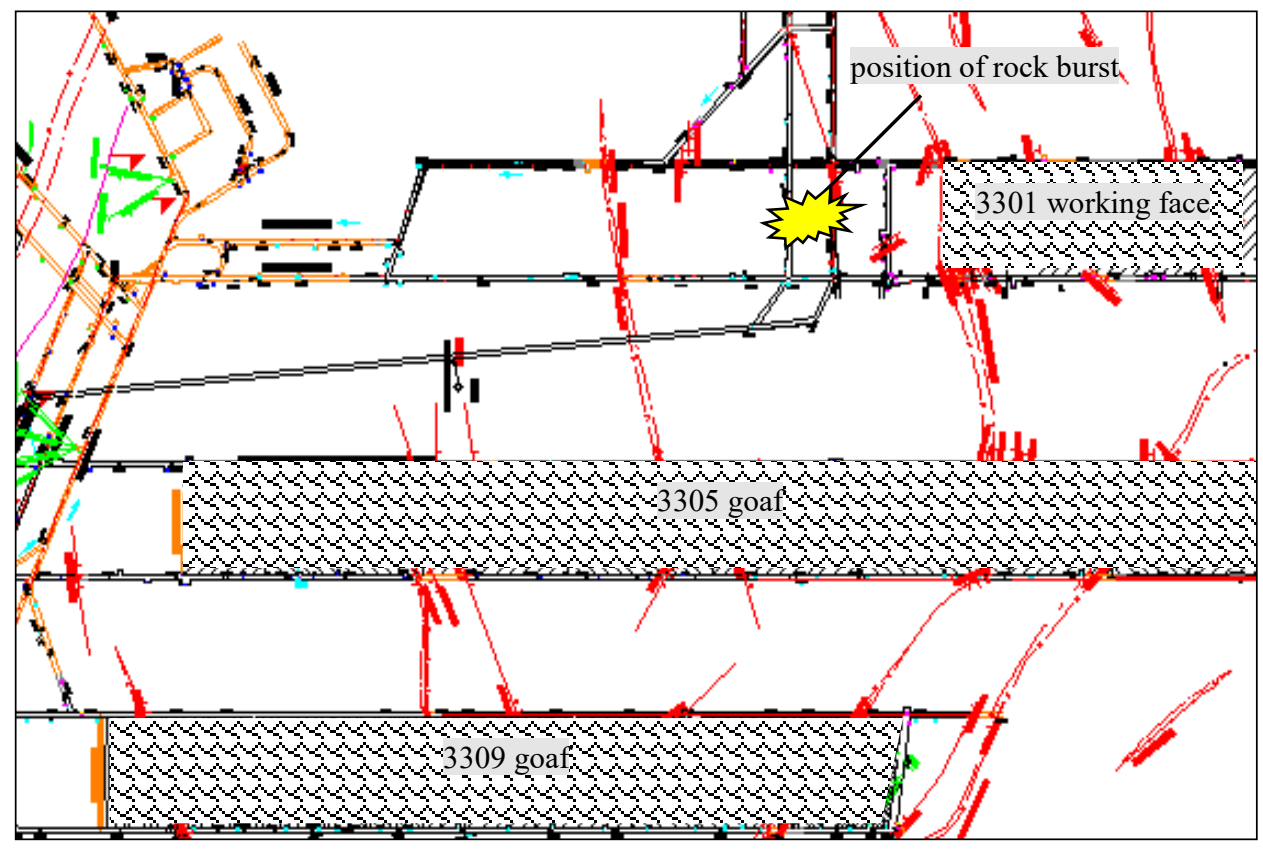

Figure 2A schematic diagram of a rock burst accident in a mine

\section{Characteristics of strip mining and its influencing factors of rock burst}

The key parameters that determine the rock burst risks are stress, surrounding rock strength, coal seam thickness, and burst tendency index of the surrounding rock rock. The strength of the surrounding rock and the overall rock burst tendency of the surrounding rock are closely related to the thickness of the coal seam ${ }^{[12]}$.

To study the relationship between coal seam thickness and rock burst risks, the relationship between the coal seam thickness and stress field distribution of roadway surrounding rock is analyzed through numerical calculation. On this basis, a mechanical model of roadway surrounding rock is established. The surrounding rock stress, rock burst tendency, stress and strength ratio and other influencing factors are comprehensively considered to study the relationship between the coal seam thickness and the rock burst risks.

\subsection{Characteristics of deep well strip mining}

In deep well strip mining, strip coal pillars are provided to support the overlying strata to control surface subsidence. After the solid strip working face was recovered, the isolated island strip underwent compression deformation under the combined action of the lateral support pressure of the goaf on both sides and the weight stress of the overlying strata ${ }^{[13]}$. After the coal pillar was compressed, the overlying strata moved and deform. Due to the existence of a hugely thick and hard key stratum in the overlying strata. The hugely thick and hard key stratum controls the movement of the overlying strata. The key strata and their upper strata do not move in concert with the underlying strata. Large-scale separation between the key stratum and the lower rock stratum occurred. Therefore, the coal pillars would not be able to effectively support the overlying strata and the stress would be redistributed. The load of the key strata and their overlying strata would be transferred to the periphery of the separation zone, resulting in stress concentration within a certain range around the separation zone.

Figure 3 shows the contour map of displacement of the strip mining area in the vertical direction. As can be seen from the figure, after the strip working face was recovered, the overlying strata below the thick and hard critical strata above the goaf of the strip working face bent, deformed or even collapsed. The thick and hard key layer was separated from the underlying rock layer. The displacement contour of the overlying strata was an arched structure, as shown in Figure 3. 


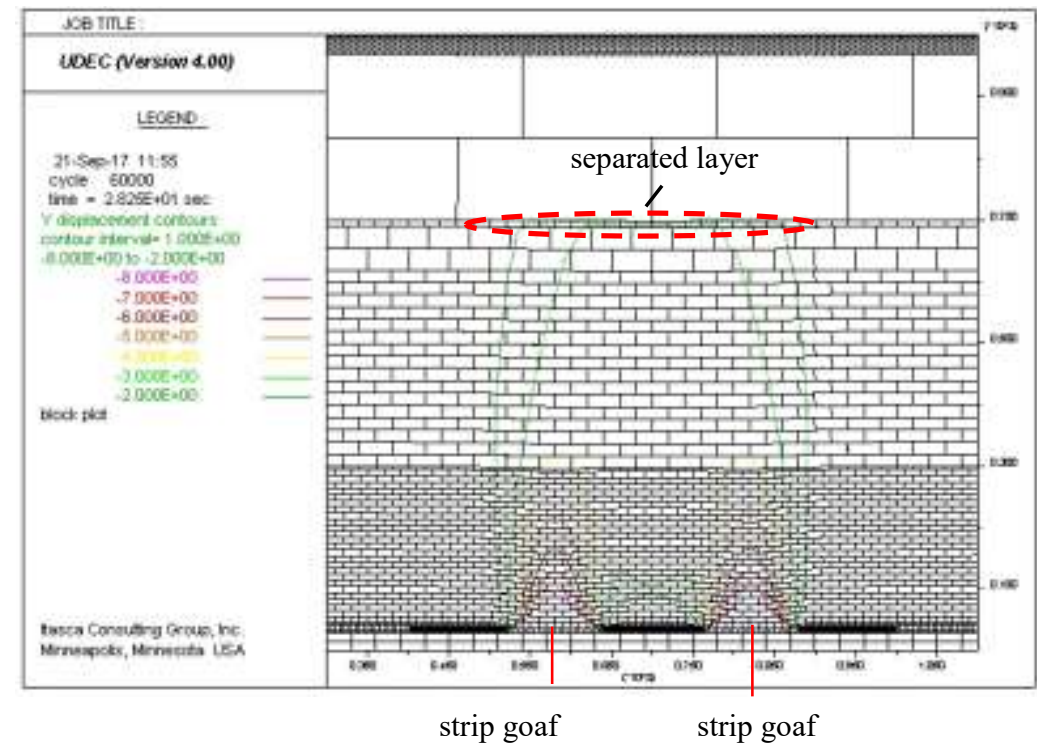

Figure 3 Displacement contour map of strip mining area

To quantitatively analyze the law of vertical displacement of the overlying strata in the strip mining area after strip mining, two survey lines were arranged in the critical rock stratum of the model. The locations of the survey lines are shown in Figure 4. After the strip excavation was finished, the vertical displacement data of the survey line in the model was exported and used to plot a curve as shown in Figure5. It can be seen from the figure that at the distance of $580 \mathrm{~m}$ and $820 \mathrm{~m}$ from the model boundary, that is, the middle position of the goaf of the mined strip corresponds to the largest amount of separation of the lower layer of the critical rock stratum. After the excavation of the strip working face, as the roof above the coal seam collapsed, the rock mass below the entire critical stratum bent and deformed, and the critical stratum was separated from the rock stratum below it.

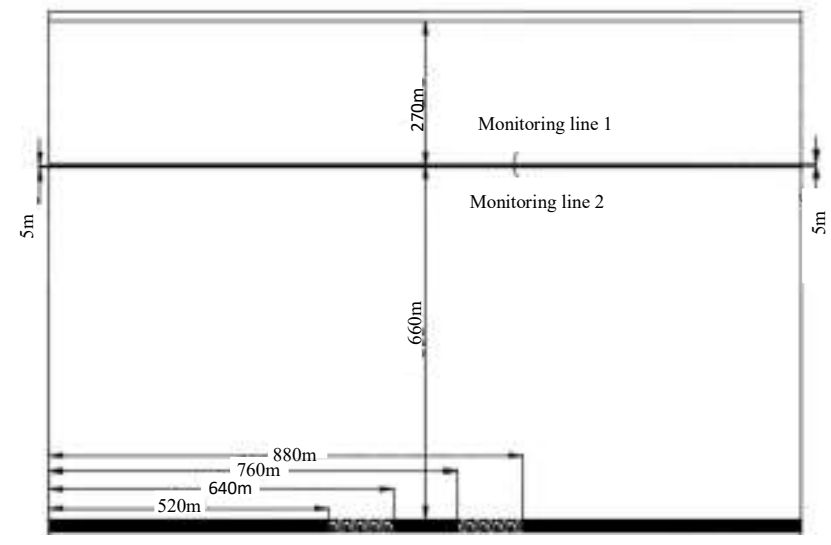

Figure 4 Schematic diagram of simulated excavation plan and monitoring line layout 


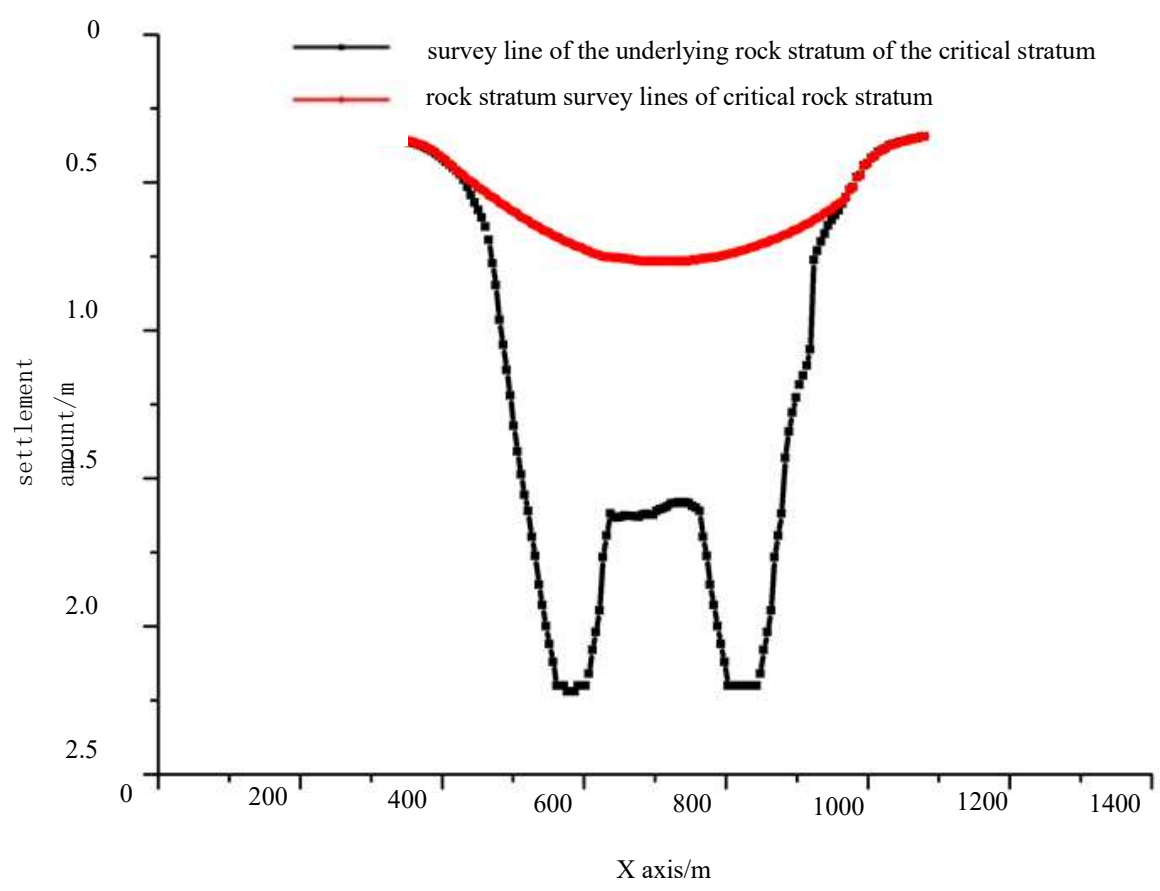

Figure5 Vertical displacement curve of the thick critical stratum and the strata below it in the strip mining area

Figure6is a cloud map of the stress distribution in the strip mining area. It can be seen from the figure that after the adjacent strips are mined, the coal pillars in the middle strip and the solid coals on both sides undergo stress concentration. The stress concentration of solid coal on both sides is greater than that of strip coal pillars, and the stress is up to $35 \mathrm{MPa}$. The numerical calculation results are close to the stress estimation results, exceeding the critical stress of $27.5 \mathrm{MPa}$ for rock bursts. It can be seen that excavation activities at the coal pillar edges in the strip mining area can easily induce rock bursts.

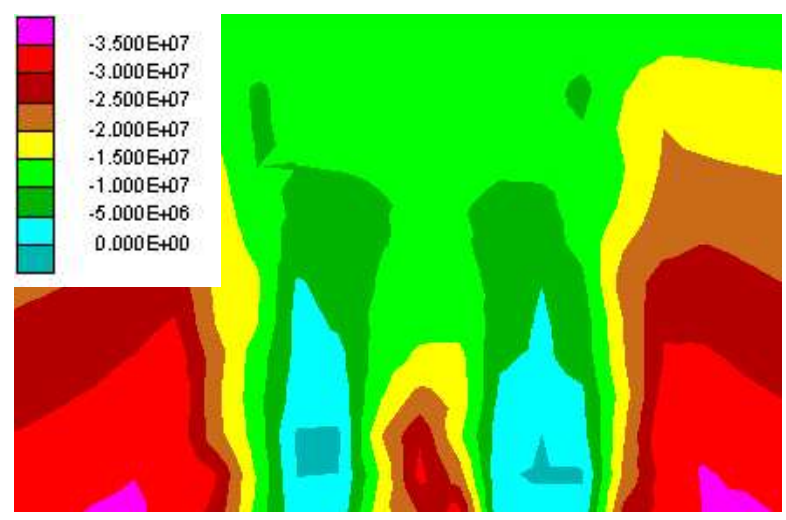

Figure6 Cloud map of stress distribution in strip mining area

\subsection{Mechanism of rock burst around large-scale separation zone in deep well strip mining}

In deep well strip mining, strip coal pillars are provided to support the overlying strata to control surface subsidence. After the strip working face was recovered, the strip coal pillars underwent compressive deformation under the combined action of the lateral supporting pressure of the goaf on both sides and the weight stress of the overlying strata. After the coal pillar was compressed, the overlying strata would move and deform. As the overlying strata has a thick and hard critical stratum, the critical stratum controls the movement of the rock stratum above the critical stratum. The critical stratum and the rock stratum above the critical stratum do not move 
in coordination with the rock stratum below. Large-scale separation occurred between the critical stratum and the underlying rock stratum. Therefore, the coal pillars would be unable to effectively support the overlying strata and the stress would be redistributed. The load of the critical strata and their overlying strata would be transferred to the periphery of the separation zone, resulting in stress concentration within a range around the separation zone, and even rock bursts, as shown in Figure7.

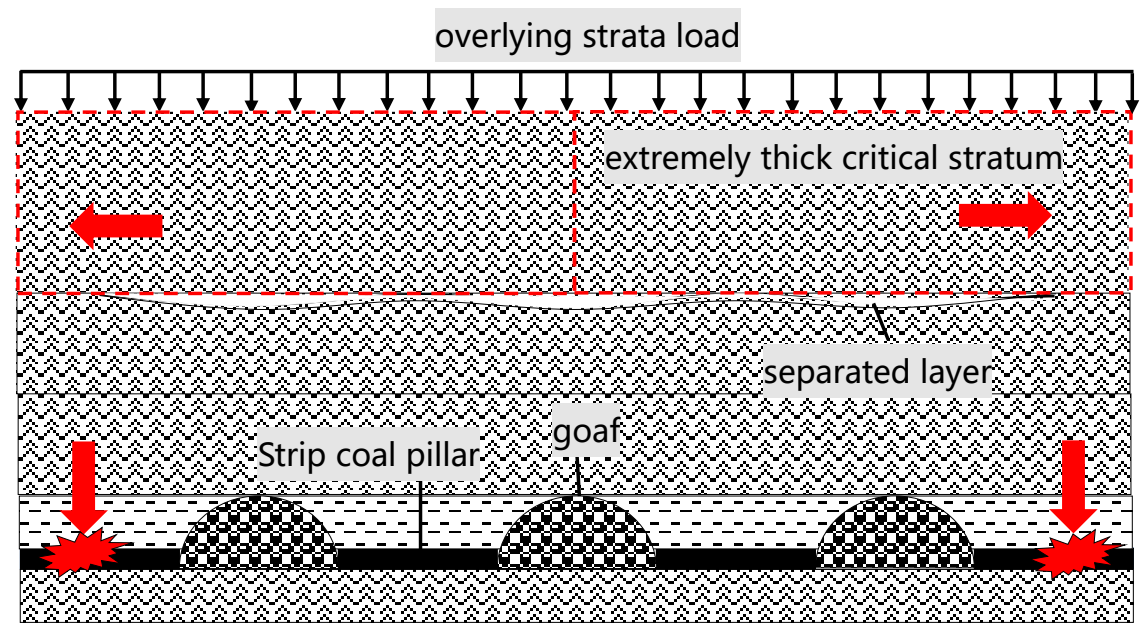

Figure7 Schematic diagram of the rock burst mechanism around the separation zone in deep well strip mining

\section{Estimation of overlying strata structure and supporting pressure in strip mining}

Different stratum structures and mining conditions will form different spatial structures of overlying strata. The movement of the overlying strata and the structure formed determine the law of change and distribution characteristics of stope supporting pressure. Under the conditions of deep well strip mining, the evolution law of the overlying strata structure and the spatial structure of the overlying strata have significant characteristics.

\subsection{Overlying strata structure and supporting pressure distribution in deep well strip mining}

Figure 8 shows the distribution characteristics of the overlying strata structure in the strip mining of the extremely thick and hard rock strata in the deep well. After the strip working face was recovered, regional separation occurred in the extremely thick and hard rock stratum above the mining area. The rock stratum above the separation stratum formed a stress transfer structure, resulting in stress concentration on both sides of the area edge. The supporting pressure of the coal seam at the edge of the strip mining area consists of three parts: The gravity of the rock strata below the separation line, the stress transferred from the top of the goaf of the mining strip to the rock strata in the separation zone, and the stress transferred from the separation position to the overlying strata on the surface are shown by the action of the strata in the dotted line in the figure on the edge coal seam in the separation zone. It can be seen fromFigure 8 that before the extremely thick and hard critical stratum is broken, the wider the separation zone is, the greater the weight transferred from the separation zone to the surface rock stratum to both sides will be. The higher the degree of stress concentration in the marginal coal seam, the higher the possibility of rock bursts occurring during mining activities at the margins of the separation zone will be. 


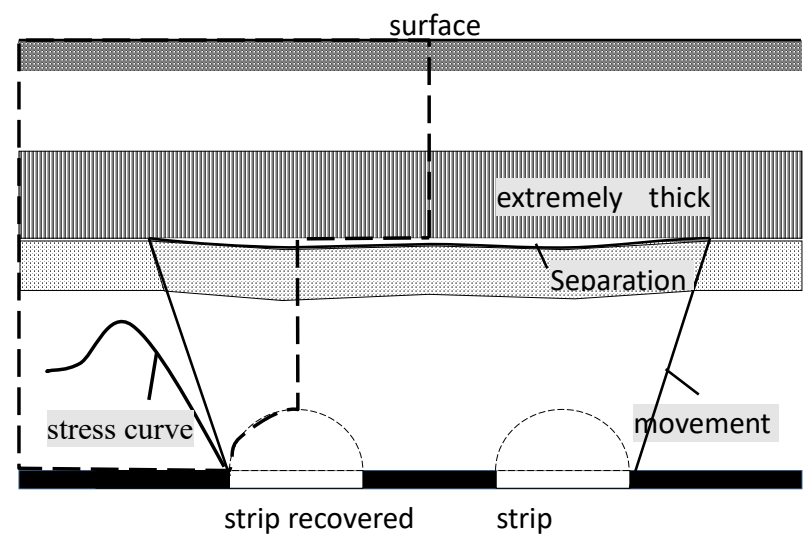

Figure 8 Structure characteristics of overlying strata in strip mining of extremely thick and hard strata in deep wells

\subsection{Calculation model and estimation of supporting pressure distribution}

After the wide strip working face with thick topsoil in the deep well was recovered, the low-level rock strata caved in to fill the goaf. As no "skeleton" of the critical stratum exists in the stratum, after the low-level rock strata caved in, the rock strata that had not caved in settled and the rock strata moved and developed to the surface, resulting in surface subsidence. In other words, the weight above the "immediate loading zone" until the overhanging part of the surface rock stratum was transferred to both sides, and the load carried by the coal on both sides increased substantially. If the adjacent strip working face was arranged within the influence range of the goaf of the mining strip working face, the risks of rock burst during the mining of the adjacent strip working faces would increase significantly.

The supporting pressure $\sigma_{1}$ of the coal on the side of the separation zone in strip mining consists of three parts: self-weight stress $\sigma_{\mathrm{q}}$, stress increment $\Delta \sigma 1$ from upper part of the goaf of the mined strip to the rock strata transfer in the separation zone, and stress increment $\Delta \sigma_{2}$ transferred from the separation zone to the surface rock strata.

$$
\sigma_{1}=\Delta \sigma_{1}+\Delta \sigma_{2}+\sigma_{q}
$$

The theoretical calculation model of lateral supporting pressure in Reference [14] is used to calculate the lateral supporting pressure distribution of the thick surface soil strip mining face in deep mines. The lateral supporting pressure $\sigma$ of the coal on one side of the goaf is composed of the self-weight stress $\sigma_{q}$ and the stress increment $\Delta \sigma$ :

$$
\sigma=\Delta \sigma+\sigma_{q}
$$

where, $\Delta \sigma$ is equal to the sum of the pressure transferred from the exposed part of each critical stratum above the goaf to either side of the coal, namely $\Delta \sigma=\Sigma \sigma_{\mathrm{i}}, i=1 \sim \mathrm{n}$.

The stress increment transferred from the $i$-th critical stratum to the coal on either side of the goaf is:

$$
\Delta \sigma_{i}= \begin{cases}\frac{\sigma_{\text {imax }} x \tan \alpha}{H_{i}} & \left(0 \leq x \leq H_{1} \cot \alpha\right) \\ 2 \sigma_{\text {imax }}\left(1-\frac{x}{2 H_{i} \cot \alpha}\right) & \left(H_{i} \cot \alpha \leq x \leq 2 H_{i} \cot \alpha\right) \\ 0 & \left(x \geq 2 H_{i} \cot \alpha\right)\end{cases}
$$

The stress $\sigma_{\mathrm{q}}$ generated by the self-weight is: 
$\sigma_{q}= \begin{cases}\frac{\gamma L_{1}}{2} & \left(0 \leq x \leq \frac{L_{1} \cot \alpha}{2}\right) \\ \gamma x \tan \alpha & \left(\frac{L_{1} \cot \alpha}{2} \leq x \leq H \cot \alpha\right) \\ \gamma H & (x \geq H \cot \alpha)\end{cases}$

surface

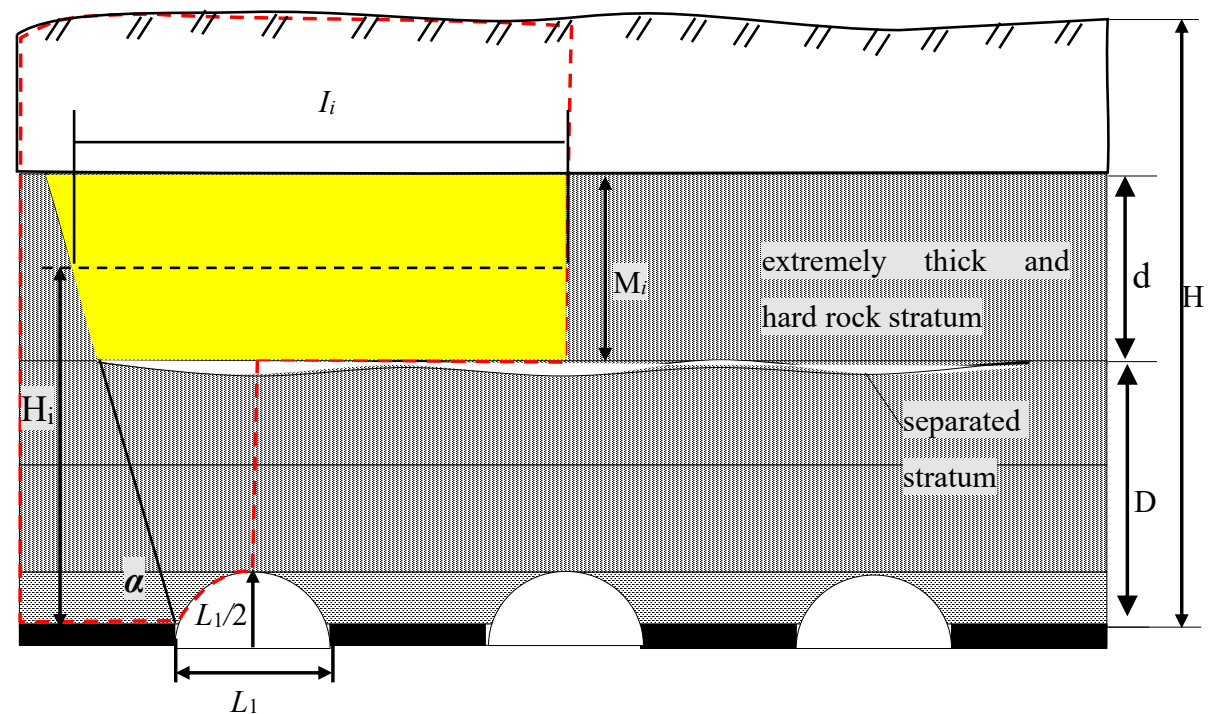

Figure 9 Calculation model of the lateral supporting pressure distribution in the strip mining goaf

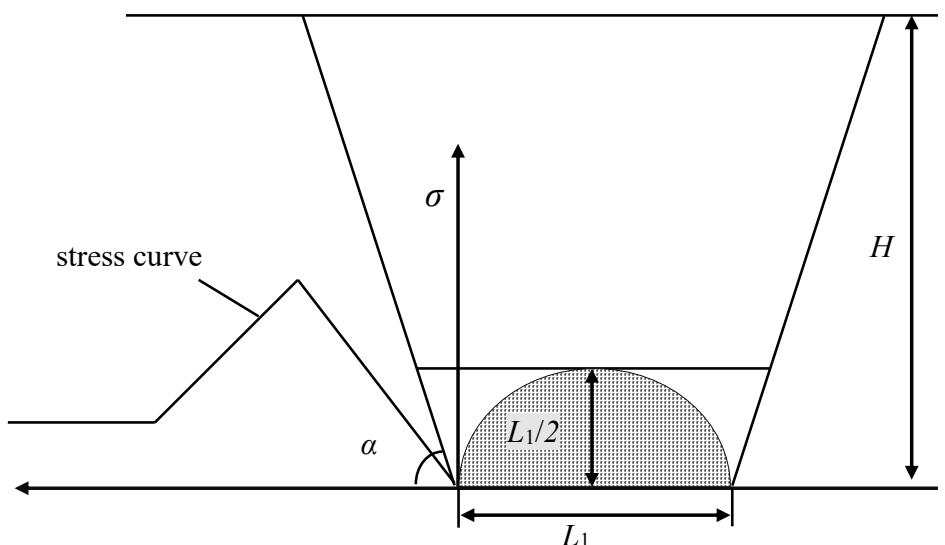

Figure 10 Calculation model of lateral supporting pressure distribution in the strip mining goaf

\section{Method and process for evaluating risks of rock burst}

Experts and scholars both at home and abroad have conducted a great deal of research on the methods for evaluating risks of rock burst, and have attained abundant research achievements. However, these evaluation methods are mostly of qualitative evaluation, and the evaluation results generally have significant errors. This substantially reduces the management efficiency of rock burst and results in the loss of human and financial resources. Therefore, the quantitative evaluation results are particularly important for the prevention and control of rock bursts.

At present, the macroscopic evaluation method and the multi-factor coupling evaluation method are widely employed in evaluation of rock burst risks. The macroscopic evaluation method can rate the possibility of rock burst; the multi-factor coupling evaluation method can define the hazardous area and risk levels by qualitative assessment. To improve the accuracy and rationality of evaluation of rock burst of the working face under the 
conditions of deep well strip mining, this chapter proposes the concept of equivalent surrounding rock strength on the basis of previous research results with the coal seam thickness as a contributing factor, thus improving the conventional multi-factor coupling evaluation method for rock burst risks. The macroscopic evaluation method and the quantitative evaluation method for rock burst risks based on stress superimposition are combined to determine the areas of rock burst risks and the risk levels. The evaluation process of rock burst risks under the conditions of deep well strip mining is shown in Figure 11.

\subsection{Possibility Index Method}

Research has indicated that rock burst is the result of a combination of various factors, and the stress state and the nature of the coal rock mass are decisive factors. Therefore, the possibility index diagnosis method with mining-induced stress and rock burst tendency as the main indicators is adopted as the basic method. Meanwhile, other method such as numerical analysis and engineering analogy are utilized for comprehensive evaluation.

The possibility index diagnostic method is a method for evaluating rock burst risks based on mining-induced stress and rock burst tendency. This method judge the possibility of rock burst by calculating the degree of membership of a stress state and rock burst tendency index to "occurrence of rock burst" with the fuzzy mathematics theory ${ }^{[15]}$.

The degree of membership of the stress state to the event of "occurrence of rock burst":

$$
U_{I_{c}}= \begin{cases}0.5 I_{c} & I_{c}<1.0 \\ I_{c}-0.5 & 1.0 \leq I_{c}<1.5 \\ 1 & I_{c} \geq 1.5\end{cases}
$$

where, $I_{c}=\sigma /\left[\sigma_{c}\right], \sigma=k \gamma H, k$ is the stress concentration factor, $\gamma$ is the average bulk density of the overlying strata, $H$ is the burial depth, and $\left[\sigma_{c}\right]$ is the uniaxial compressive strength of the coal.

The degree of membership of the rock burst tendency index to the event of "occurrence of rock burst":

$$
U_{\text {Wet }}=\left\{\begin{array}{lc}
0.3 \text { Wet } & \text { Wet }<2.0 \\
0.133 \text { Wet }+0.333 & 2.0 \leq \text { Wet }<5.0 \\
1 & \text { Wet } \geq 5.0
\end{array}\right.
$$

where, Wet is the rock burst tendency index of coal seam.

Possibility index of possibility of burst rock:

$$
U=\left(U_{I c}+U_{W e t}\right) / 2
$$

According to the possibility index $\mathrm{U}$, the possibility of rock burst occurrence is evaluated, and the evaluation standard is shown in Table 1.

Table 1 Evaluation criteria for the possibility of rock burst

\begin{tabular}{ccccc}
\hline $\mathrm{U}$ & $0 \sim 0.6$ & $0.6 \sim 0.8$ & $0.8 \sim 0.9$ & $0.9 \sim 1.0$ \\
\hline possibility & impossible & possible & probable & able to \\
\hline
\end{tabular}

\section{2 process of evaluation of rock burst risks}

The basic content and steps of the possibility index diagnosis method are:

(1) Calculate the distribution law of mining stress field; 
(2) Test and calculate the rock burst tendency of coal rock mass;

(3) Calculate the respective degrees of membership of stress and rock burst tendency to the event of "occurrence of rock burst";

(4) Calculate the possibility index of rock burst

(5) Diagnose the possibility of rock burst at a certain point.

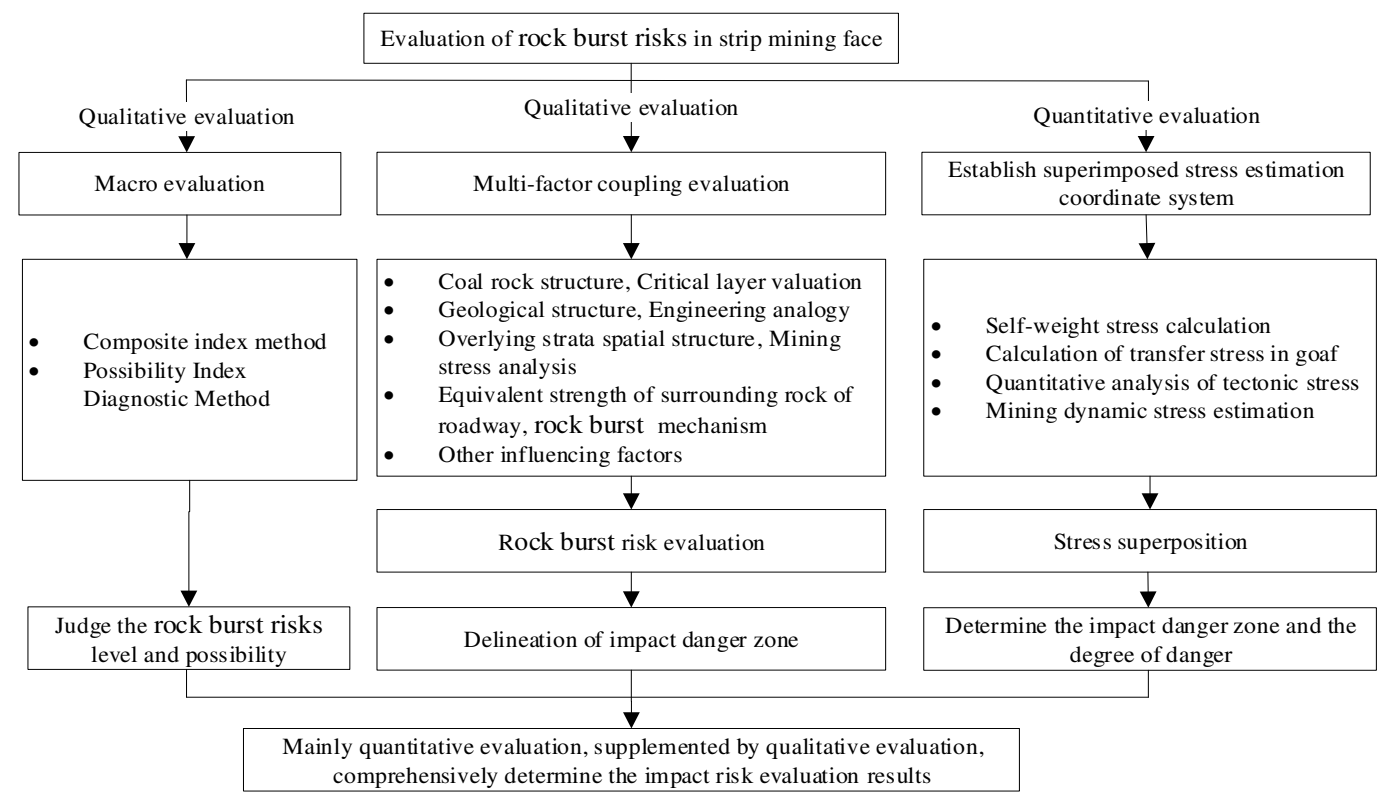

Figure 11 Evaluation process of rock burst risks in deep well strip mining

\section{Engineering Applications}

\subsection{Engineering background}

The 4203 fully mechanized mining face of a mine in Shanxi is located on the north side of the 4th main roadway, adjacent to the Dongpo mine field on the west and the north. Between the two are the coal pillars for protection of mine boundaries; in the east of the 4203 face is the 4202 goaf, which is separated by section coal pillars (20m wide). The working face has a strike length of $1091 \mathrm{~m}$, a slope length of $215 \mathrm{~m}$, an average coal seam thickness of $5.68 \mathrm{~m}$, and a coal seam inclination of 2 to $14^{\circ}\left(5^{\circ}\right.$ on average). The strike longwall fully mechanized coal mining method is adopted, and the roof is managed by the totally caving method. The immediate roof and upper roof of the working face are medium-coarse sandstone and mudstone with the cracks not developed. The thickness of the immediate roof is $5.95 \mathrm{~m}$, which belongs to the Class I stable roof (medium hard roof). The thickness of the upper roof is $3.97 \sim 9.04 \mathrm{~m}$. The immediate floor and upper floor of the working face It is mudstone and fine sandstone with undeveloped fissures. The thickness of the immediate floor is $3.91 \sim 9.35 \mathrm{~m}$, and the thickness of the upper floor is $5.88 \mathrm{~m}$.

According to the rock burst tendency report on the mine, the 4th coal seam of the mine have a weak rock burst tendency, with uniaxial compressive strength of $18.89 \mathrm{MPa}$. The 2 th rock stratum of the 4 th coal seam roof has weak rock burst tendency, and the 1st rock stratum of the 4th coal seam roof has strong rock burst tendency. The 9th coal seam has a strong rock burst tendency with uniaxial compressive strength of 19.40MPa. The rock stratum of the 9th coal seam roof has a strong rock burst tendency, and the rock stratum of the 9th coal seam floor has a weak rock burst tendency. 


\subsection{Evaluation of Rock Burst Risks}

(1) distribution law of mining stress field

According to the mining conditions around the 4203 working face, the stress in the accident area is estimated as follows:

(1) Advance supporting pressure of 4203 working face $\sigma_{1}$ :

$$
\sigma_{1}=K_{1} \gamma H=2 \times 0.025 \times 400 M P a=20 M P a
$$

In the formula (8), $\mathrm{K}_{1}$-advance support pressure concentration factor of the working face, 2 . The advance support pressure concentration factor of the general working face is $1.5 \sim 1.8$, but the hydrodynamic effect of the goaf of three working faces of the 4th coal stratum and the island-like working surface effect caused by large boundary faults should be comprehensively considered for this working face. $\gamma$ - stratum bulk density, generally $25 \mathrm{kN} / \mathrm{m}^{3} ; \mathrm{H}$ - the average mining depth of the accident area, $400 \mathrm{~m}$.

increment of lateral supporting pressure on the 4202 working face $\Delta \sigma_{2}$

The 4202 working face has been mined, and the static lateral residual supporting pressure concentration coefficient $\mathrm{K}_{2}$ is set to 1.2 . Then, the lateral supporting pressure increment is:

$$
\Delta \sigma_{2}=\left(K_{2}-1\right) \sigma_{1}=0.2 \times 20 M P a=4 M P a
$$

supporting pressure increment behind the 9202 working face $\Delta \sigma_{3}$

The average thickness of the 9th coal seams is $15.92 \mathrm{~m}$, an extremely thick coal seam. Top coal caving is used for the 9202 working face. According to the general distribution law of the rear supporting pressure of the top coal caving working face, the distribution area of the rear supporting pressure is about $50 \sim 300 \mathrm{~m}$ behind the face. The accident area is located at $192 \mathrm{~m}$ behind the 9202 working face, within the influence range of the rear supporting pressure. When the accident occurred, the 9202 working face was still in the mining stage, and the disturbance caused by the large mining height had great stress and a wide influence range. Therefore, the stress concentration factor $\mathrm{K}_{3}$ of the rear supporting pressure was estimated according to 1.5, and the increment of the rear supporting pressure of the 9202 working face:

$$
\Delta \sigma_{3}=\left(K_{3}-1\right)\left(\sigma_{1}+\Delta \sigma_{2}\right)=0.5 \times 24 M P a=12 M P a
$$

The rock burst stress $\sigma$ of this accident is composed of the advance supporting pressure $\sigma 1$ of the working face (4203), the lateral residual supporting pressure increment $\Delta \sigma_{2}$ of the adjacent working face (4202) and the rear supporting pressure increment $\Delta \sigma_{3}$ of the lower working face (9202). i.e.:

$$
\sigma=\sigma_{1}+\Delta \sigma_{2}+\Delta \sigma_{3}=20+4+12=36 M P a
$$

According to the survey report on rock burst tendency provided by an authority, the 4th coal seam of this mine has a weak rock burst tendency with uniaxial compressive strength of $18.89 \mathrm{MPa}$. For evaluation of rock burst risks of coal mines in China, the ratio of the total stress of the surrounding rock to the unidirectional compressive strength of the surrounding rock is generally used as the evaluation index for local rock burst risks. In other words, the rock burst risk index $I_{c}=\sigma /\left[\sigma_{c}\right]$. It is generally believed that when $I_{c} \geq 1.5$, the coal seam is considered to have rock burst risks. The risk index of rock burst in the accident area of the 4203 working face is: 


$$
I_{c}=\sigma /\left[\sigma_{c}\right]=36 / 18.89=1.9 \geq 1.5
$$

It is thus clear that the accident area of the 4203 working face has the stress conditions for rock burst.

(2) Testing and calculating the rock burst tendency of coal rock mass

According to the results of the laboratory test, the rock burst tendency index of the 4-th coal seam Wet $=4.95$ has a weak rock burst tendency.

(3) The degree of membership of the stress and rock burst tendency to the event of "occurrence of rock burst"

$\mathrm{I}_{\mathrm{c}}=1.9$ was substituted into the formula(12) to get $\mathrm{U}_{\mathrm{Ic}}=1$. In other words, the degree of membership of stress to the occurrence of rock burst is 1 . Wet $=4.95$ was substituted into the formula (13) to get $U_{\text {Wet }}=0.99$, which means that the degree of membership of rock burst tendency to the occurrence of rock burst is 0.99 .

(4) Calculating the possibility index of rock burst

The possibility index is:

$$
U=\left(U_{I c}+U_{W e t}\right) / 2=0.995
$$

(5) Diagnosing the possibility of rock burst at a certain point

The possibility index $U$ of rock burst at 4203 working face is 0.995 . This means that under the combined action of the advance supporting pressure of the 4203 working face, the rear supporting pressure of the 9202 working face, and the lateral supporting pressure of the 4202 working face goaf, the 4203 working face has the stress conditions for rock burst.

\subsection{Numerical simulation verification}

According to the geological conditions of the 4203 working face and the mining conditions of the surrounding space, a two-dimensional numerical model was established, as shown in Figure 12. The model size was $655 \mathrm{~m} \times 270 \mathrm{~m}$, and divided into 7074 units and 14520 nodes. After simplification, it was determined that the model was composed of 5 rock strata. Horizontal displacement constraints were applied around the model, and vertical displacement constraints were applied at the bottom. Considering the effects of the advance supporting pressure of the 4203 working face, a uniform load of $17.5 \mathrm{MPa}$ was applied to the model. The vertical stress varied linearly with depth, and the horizontal stress was 0.5 times the vertical stress.

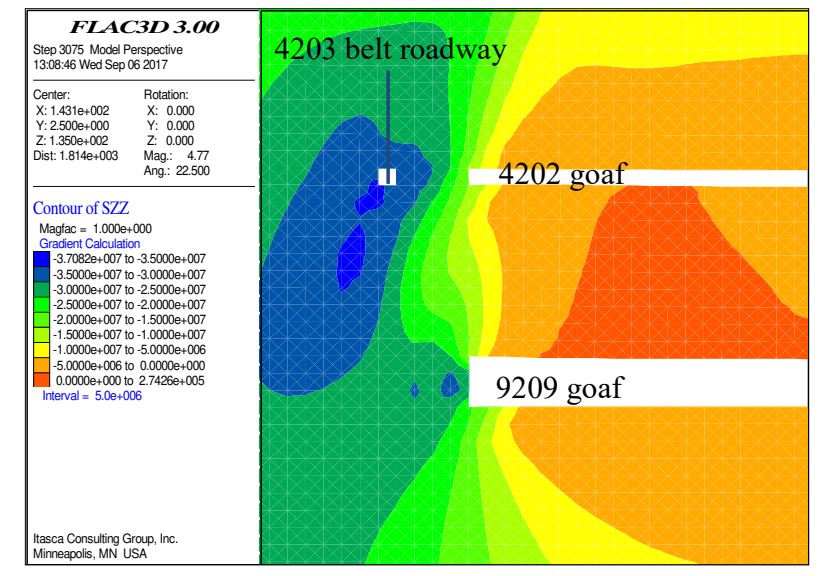

Figure 12 Cloud diagram of stress distribution in the surrounding rock of the belt roadway at the 4203 working face

As can be seen from the figure, under the effects of the advance supporting pressure of the 4203 working 
face, the transfer stress of the goaf of the 4202 working face and the transfer stress of the goaf of the 9202 working face, the concentrated stress of the coal pillar in the rock burst section of 4203 working face was up to $35 \mathrm{MPa}$. The stress was unevenly distributed, and the peak stress was close to the coal wall of the belt roadway at the 4203 working face. This result is basically consistent with the theoretical calculation result of $36 \mathrm{MPa}$.

\section{Conclusion}

Under the conditions of strip mining in deep wells, the stress increment is very great, and rock bursts may easily occur at low depths. The paper analyzes cases of major rock bursts for preventing and controlling rock bursts, and draws the following conclusions:

(1) Based on two typical deep strip mining accidents, the paper studies the characteristics of the spatial structure changes of the overlying strata caused by strip mining, and analyzes the influencing factors of rock bursts.

(2) By analyzing the change law of the overlying rock structure in strip mining, the paper studies the distribution and evolution of the supporting pressure and proposes the calculation model of supporting pressure and verifies a mine by means of estimation.

(3) By combining the above research, the paper proposes a risk evaluation model of rock burst in strip mining face based on the possibility index method for providing a theoretical basis for the management of rock bursts in coal mines.

(4) Under the context of a major rock burst accident in a mine, the paper evaluates the rock burst risks in the rock burst areas using the theoretical calculation method. The results show that the stress on the rock burst area of the 4203 working face is much greater than the critical stress of the rock burst and reveals the stress conditions for rock bursts.

\section{References}

[1] (Lan Hang, Chen Dongke, Mao Debing. Current status of deep mining and disaster prevention in China[J]. Coal Science and Technology, 2016,44(1):39-46.

[2] Jiang Fu-xing, Wang Ping, Feng Zeng-qiang, et al. Mechanism, prediction and control of"rock burst induced by shock bump"'kind dynamic accident in composite thickness coal[J]. Journal of China Coal Society, 2009, 34(12): 1605-1609.

[3] Jiang Fuxing, Shi Xianfeng, Wang Cunwen. Mechanical mechanism of rock burst accidents in slice mining face under high pressure[J]. Chinese Journal of Geotechnical Engineering, 2015,37(6): 1123-1131.

[4] Dou Linming, HE Xueqiu. Theory and technology of rock burst prevention[M]. Xuzhou: China University of Mining and Technology Press, 2001.

[5]Jiang Fuxing, Wang Cunwen, Ye Genxi, et al. Study on possibility evaluation method of coal outburst in longwall face[C]// Proceedings of National Symposium of the 2008 Rock Burst Seminar. Xuzhou: China University of Mining and Technology Press,2008:91-96.

[6] Zhang Hongwei, Zhu Feng, Han Jun, et al. Geological dynamic conditions and forecast technology for rock bursts[J]. Journal of China Coal Society, 2016, 41(3):545-551.

[7] Zhang Hongwei, Rong Hai, Chen Jianqiang, et.al. Geo-dynamic condition evaluation method for rockburst in suberect and extremely thick coal seam [J]. Journal of mining \& Techonlogy, 2015, 44(6):1053-1060.

[8] The National Standards Compilation Groups of People's Republic of China. GB/T 25217.2-2010 Methods for test, monitoring and prevention of rock burst-Part2: Classification and laboratory test method on bursting liability of coal[S]. Beijing: Standards Press of China,2010.

[9] Qian Qi-hu. Definition, mechanism, classification and quantitative forecast model for rockburst and pressure bump[J]. Rock and Soil Mechanics, 2014, 35(1): 1-6.

[10] Pan Yi-shan, GENG Lin, LI Zhong-hua. Research on evaluation indices for impact tendency and danger of coal seam[J].Journal 
of China Coal Society, 2010, 35(12):1975-1978.

[11] Jiang Fu-xing, Wei Quan-de, Yao Shun-li, et al. Key theory and technical analysis on mine pressure bumping prevention and control[J]. Coal Science and Technology, 2013, 41(6):6-9.

[12] Jiang Fuxing, Shu Couxian, Wang Cunwen. Impact risk appraisal of stope working faces based on stress superimposition[J]. Chinese Journal of Rock Mechanics and Engineering, 2015, 34(12): 2428-2435.

[13] Zhang Junfei, Jiang Fuxing, Yang Jianbo, et al. Recoverability of isolated coal pillars in rockburst coal seam[J]. Journal of Mining and Safety Engineering,2016, 33(5): 867-872.

[14] Liu Jinhai, Jiang Fuxing, Wang Naiguo, et al. Research on reasonable width of segment pillar of fully mechanized caving face in extra-thick coal seam of deep shaft[J]. Chinese Journal of Rock Mechanics and Engineering, 2012,3(15): 921-927.

[15] Jiang Fuxing, Liu Yi, Zhang Yichao, et al. A three-zone structure loading model of overlying strata and its application on rockburst prevention[J]. Chinese Journal of Rock Mechanics and Engineering, 2016, 35(12): 2398-2408. 
Figures
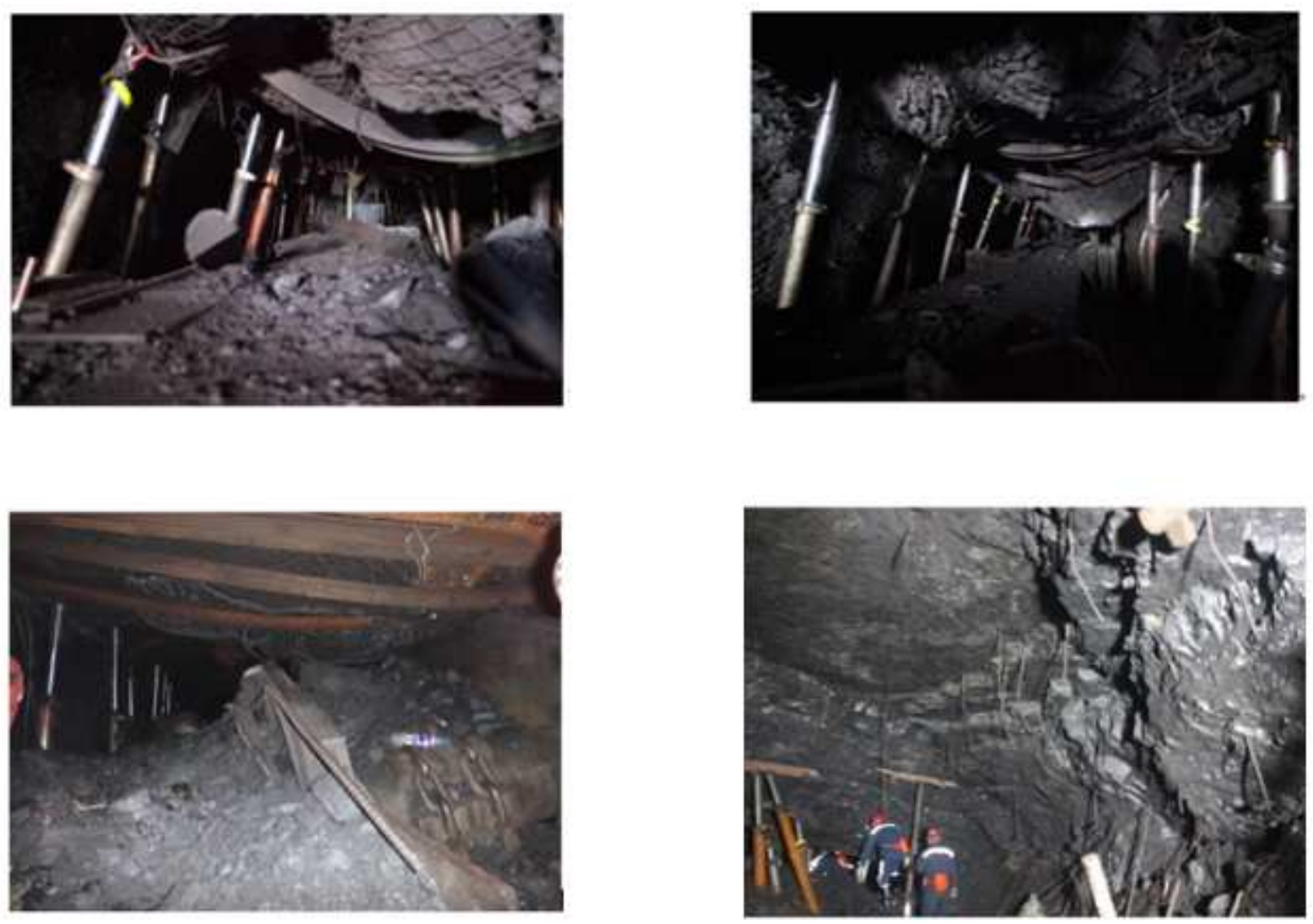

Figure 1

Scene of a rock burst accident in a mine 


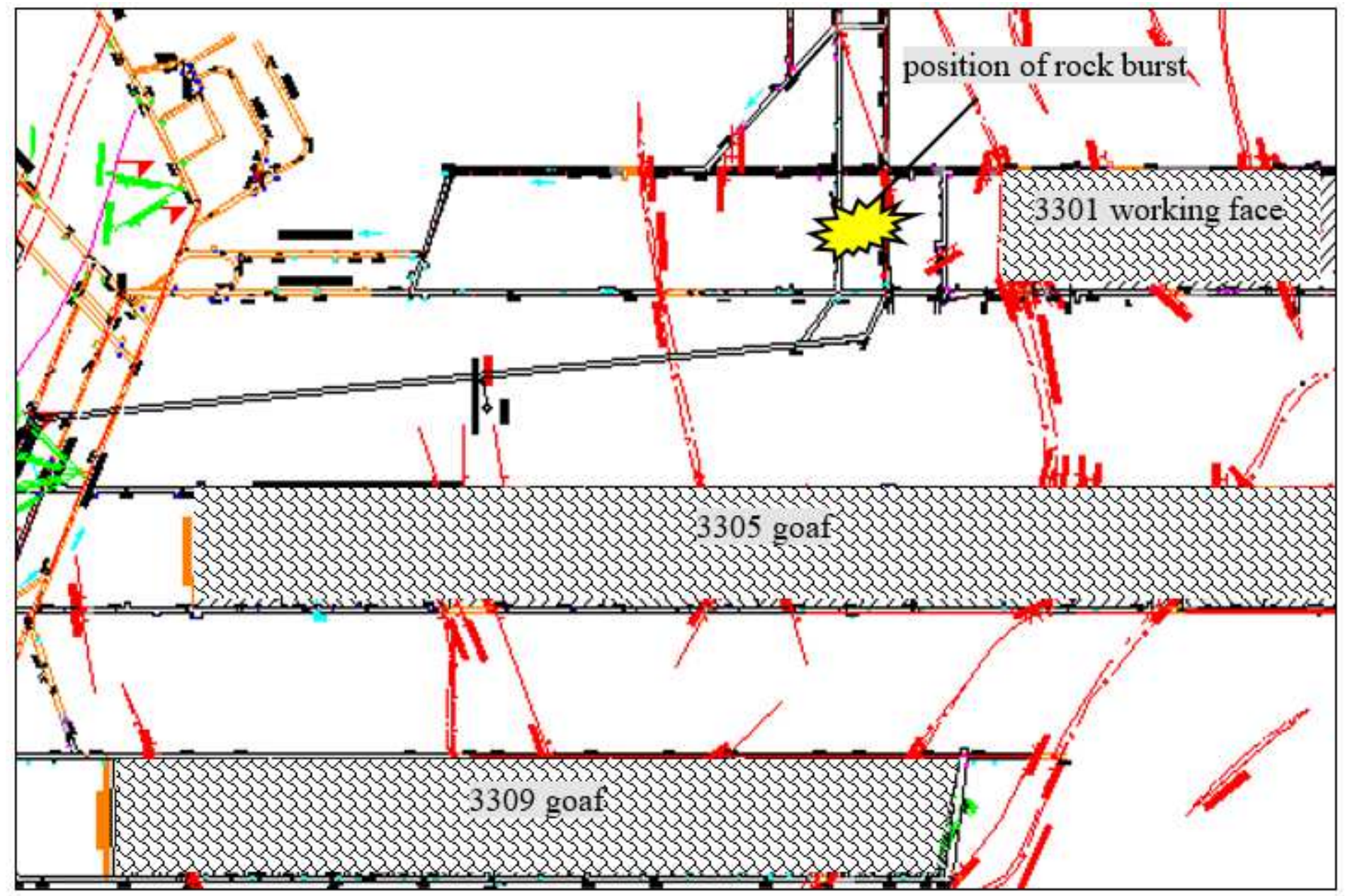

Figure 2

A schematic diagram of a rock burst accident in a mine 


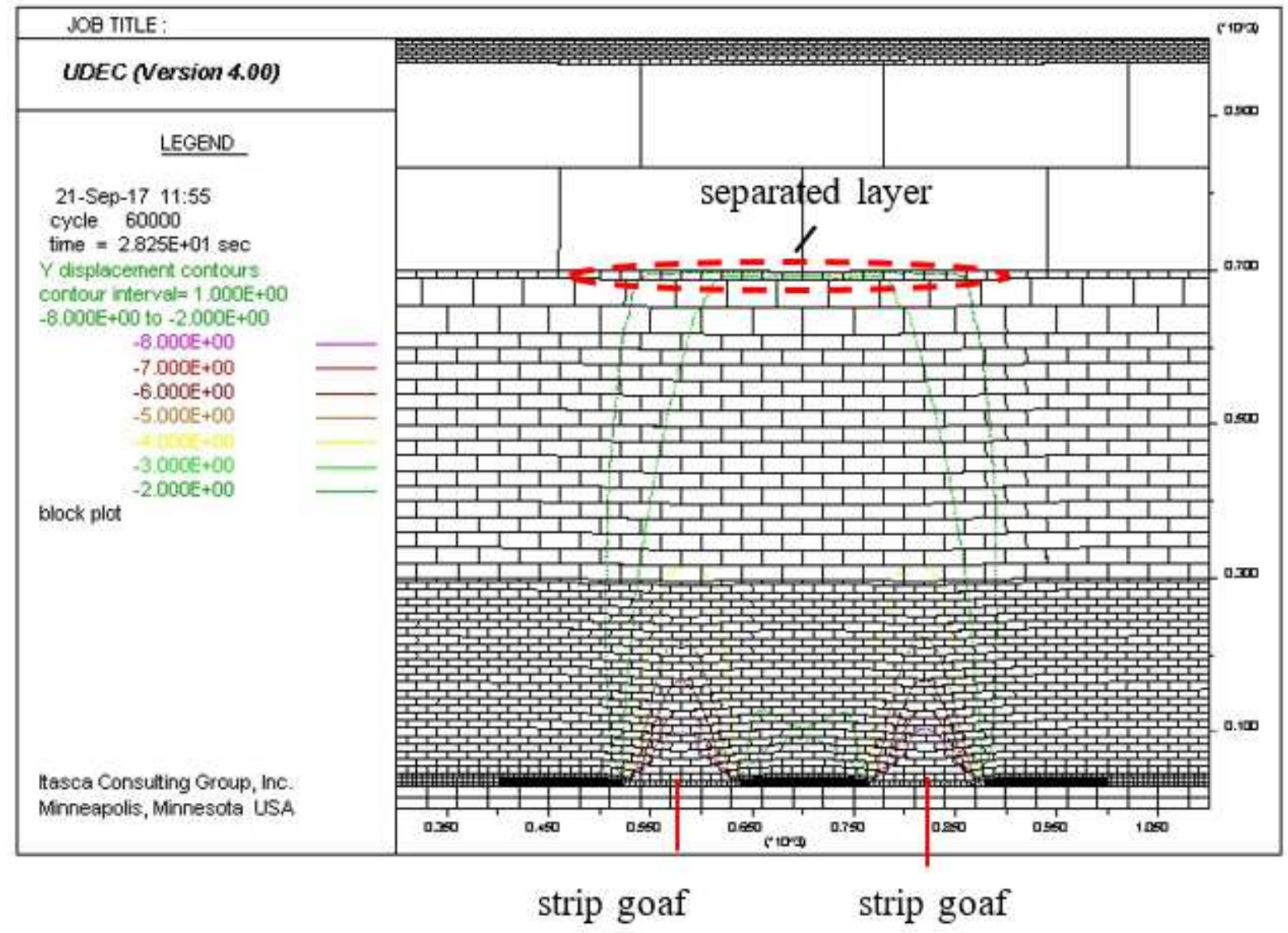

Figure 3

Displacement contour map of strip mining area 


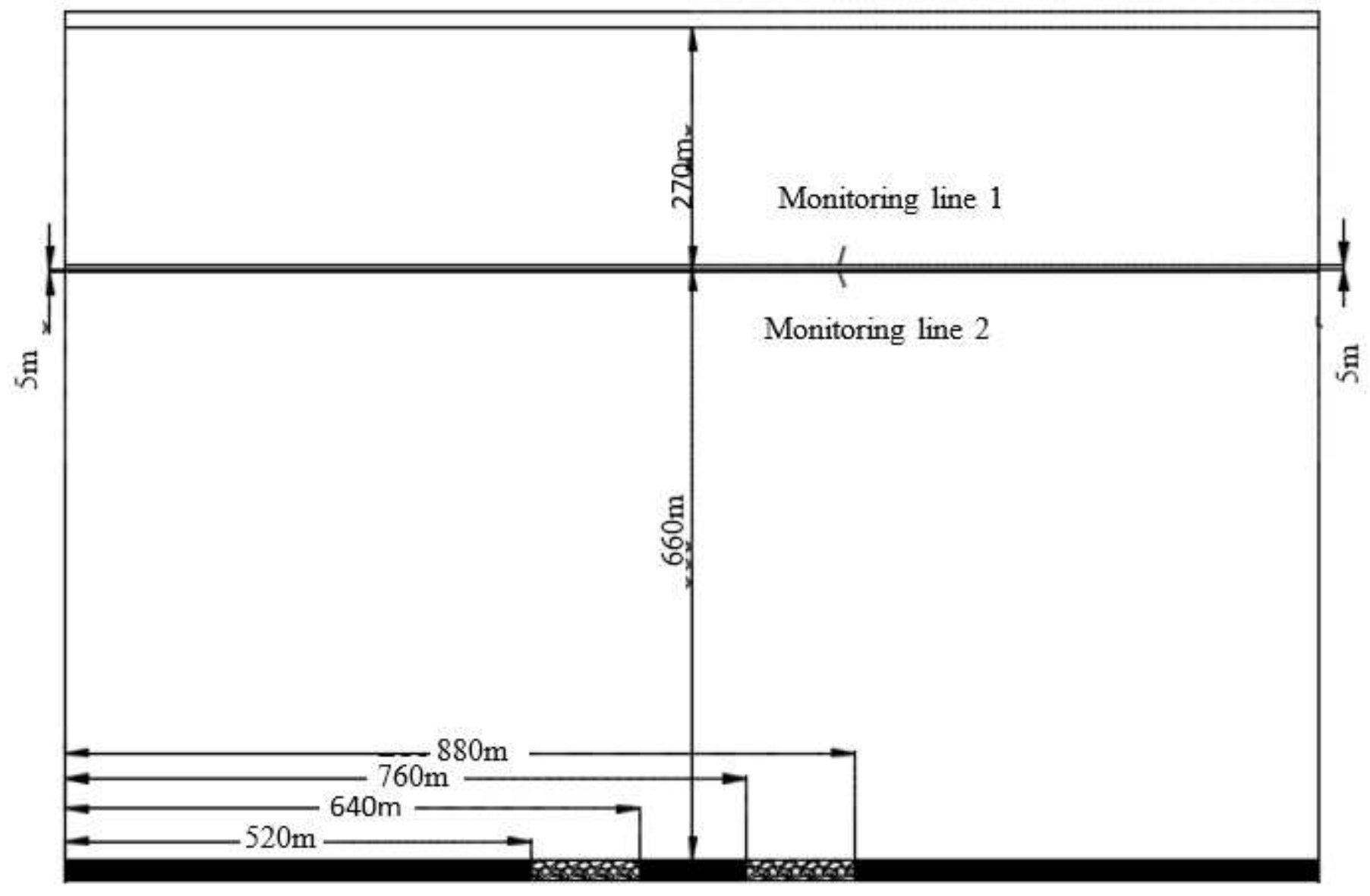

Figure 4

Schematic diagram of simulated excavation plan and monitoring line layout 


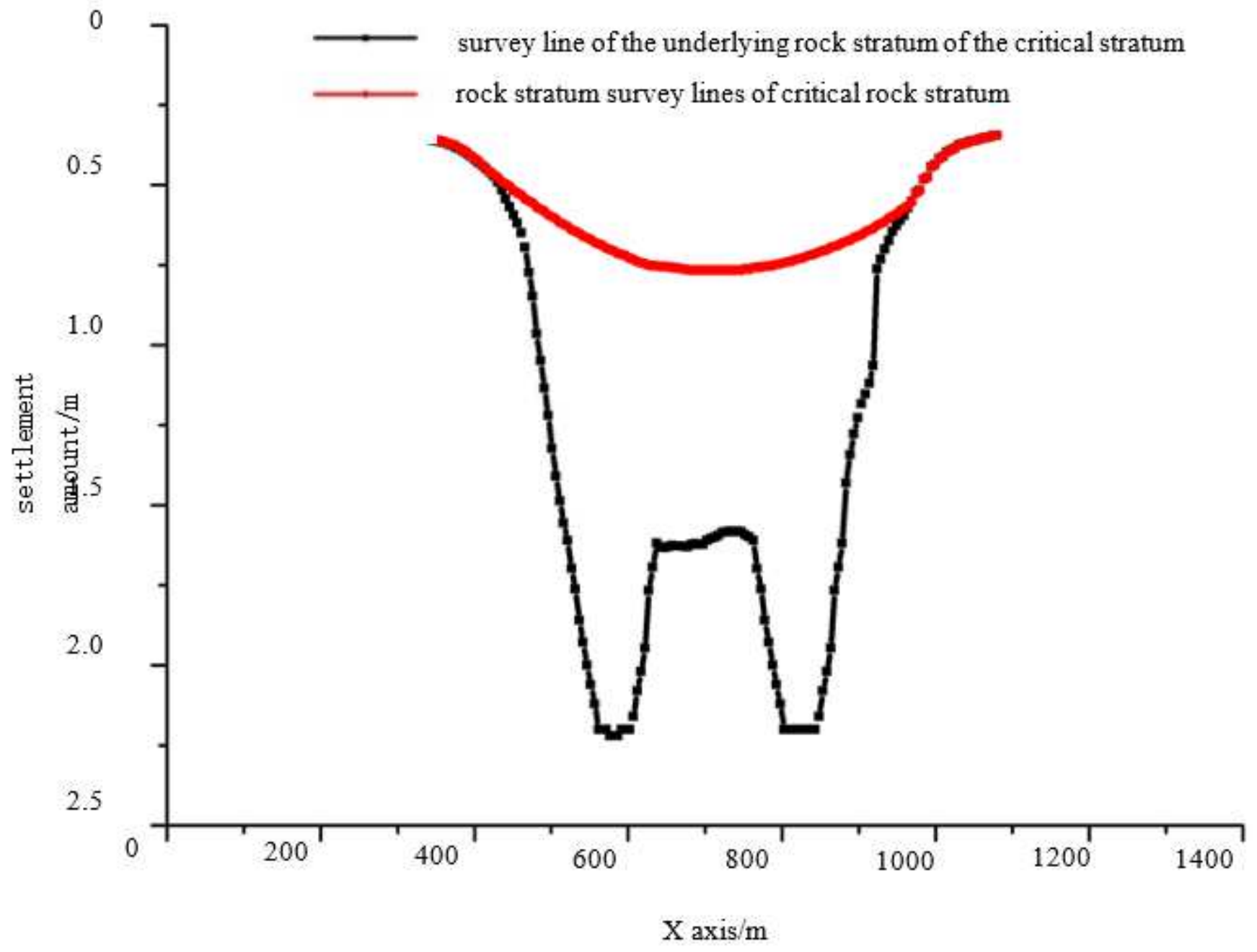

Figure 5

Vertical displacement curve of the thick critical stratum and the strata below it in the strip mining area 


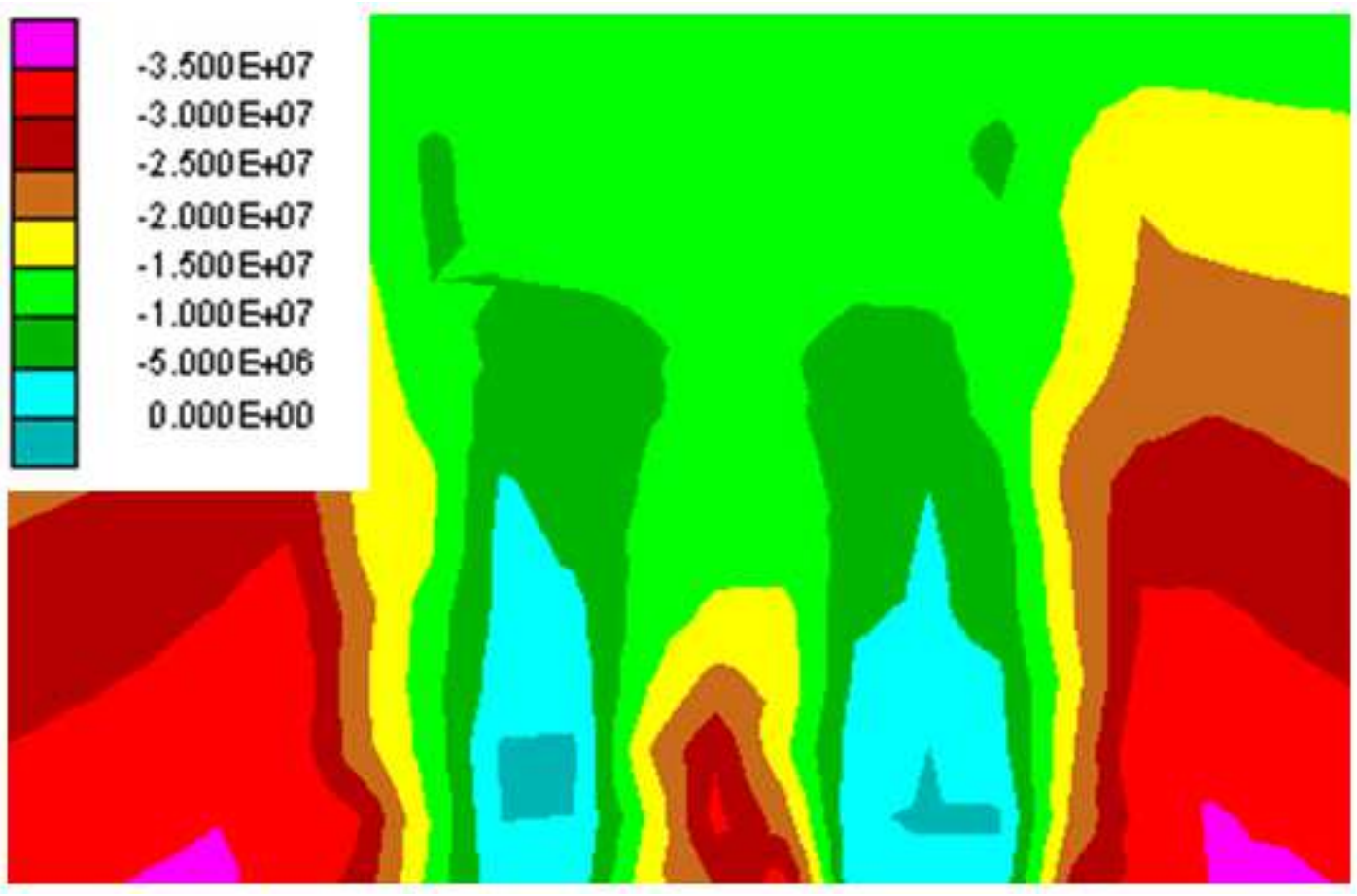

Figure 6

Cloud map of stress distribution in strip mining area

\section{overlying strata load}

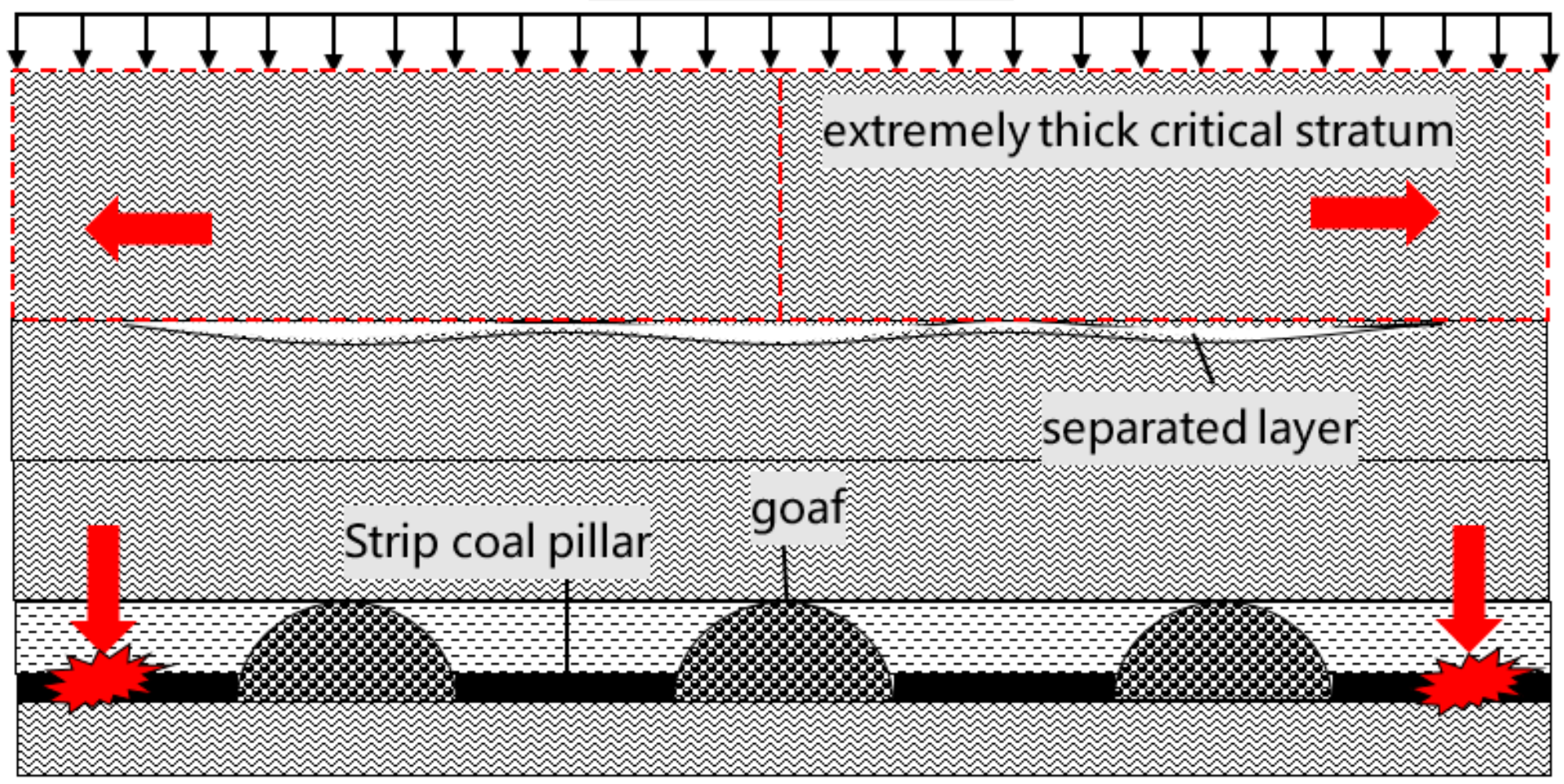

Figure 7

Schematic diagram of the rock burst mechanism around the separation zone in deep well strip mining 
surface

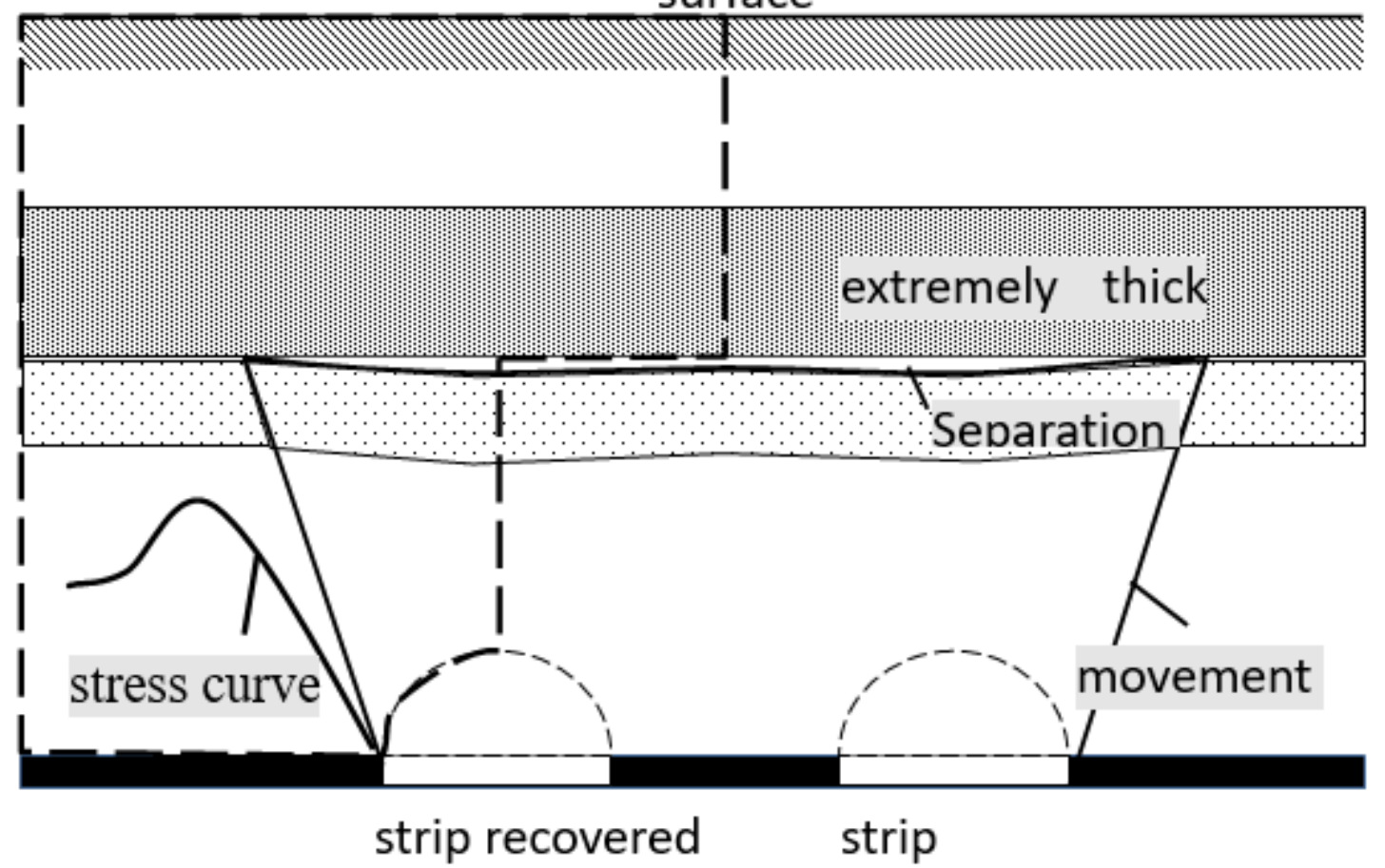

Figure 8

Structure characteristics of overlying strata in strip mining of extremely thick and hard strata in deep wells 


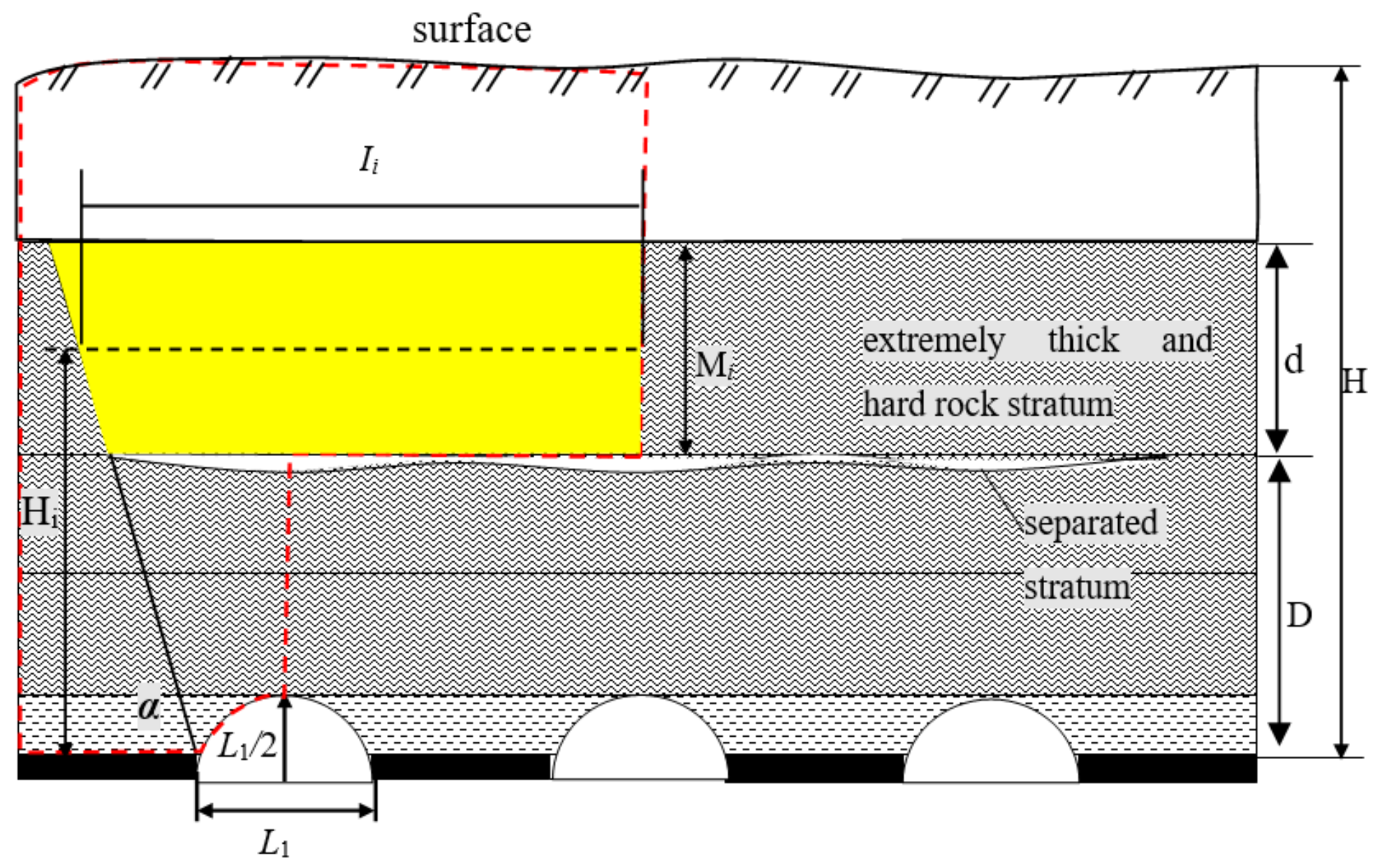

Figure 9

Calculation model of the lateral supporting pressure distribution in the strip mining goaf

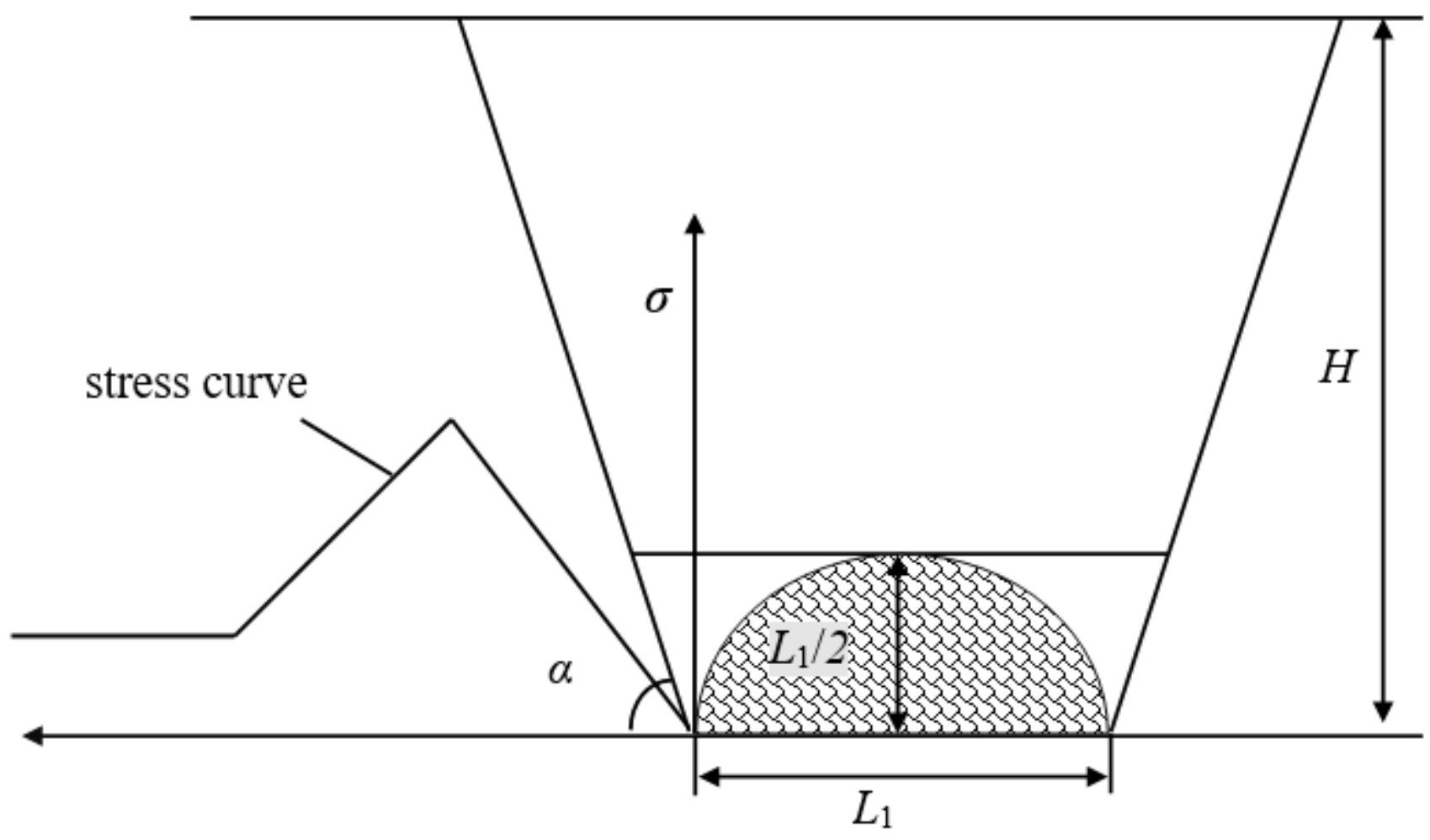


Calculation model of lateral supporting pressure distribution in the strip mining goaf

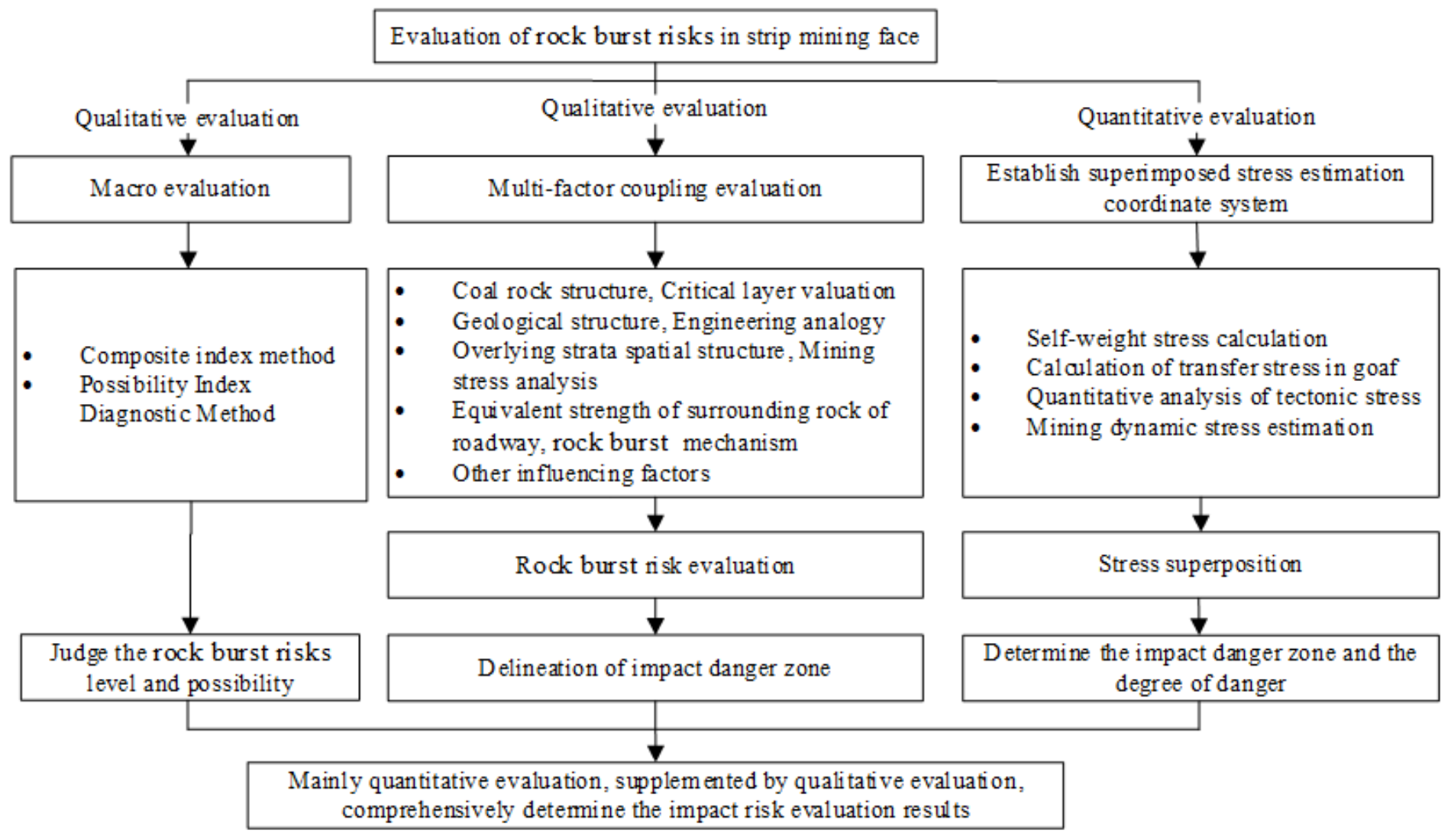

\section{Figure 11}

Evaluation process of rock burst risks in deep well strip mining

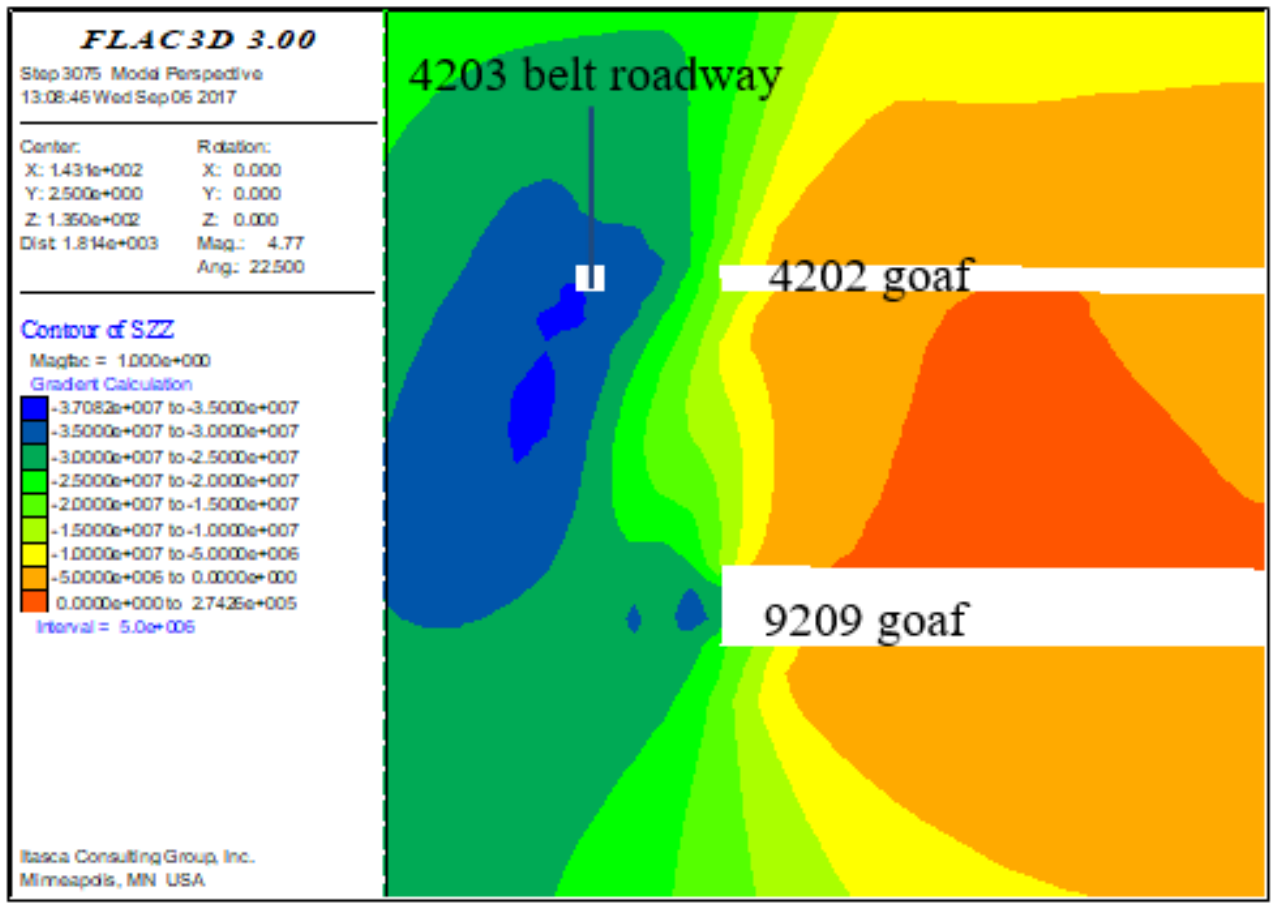


Figure 12

Cloud diagram of stress distribution in the surrounding rock of the belt roadway at the 4203 working face 